\title{
Katherine Astbury, The Moral tale in France and Germany 1750-1789
}

\section{Alessandra Rollo}

\section{(2) OpenEdition}

1 Journals

\section{Edizione digitale}

URL: https://journals.openedition.org/studifrancesi/40712

DOI: 10.4000/studifrancesi.40712

ISSN: 2421-5856

\section{Editore}

Rosenberg \& Sellier

\section{Edizione cartacea}

Data di pubblicazione: 1 juillet 2004

Paginazione: 193-194

ISSN: 0039-2944

\section{Notizia bibliografica digitale}

Alessandra Rollo, «Katherine Astbury, The Moral tale in France and Germany 1750-1789», Studi Francesi

[Online], 142 (XLVIII | I) | 2004, online dal 30 novembre 2015, consultato il 09 septembre 2021. URL: http://journals.openedition.org/studifrancesi/40712 ; DOI: https://doi.org/10.4000/studifrancesi. 40712

Questo documento è stato generato automaticamente il 9 septembre 2021.

\section{(c) (1)}

Studi Francesi è distribuita con Licenza Creative Commons Attribuzione - Non commerciale - Non opere derivate 4.0 Internazionale. 


\title{
Katherine Astbury, The Moral tale in France and Germany 1750-1789
}

\author{
Alessandra Rollo
}

\section{NOTIZIA}

KATHERINE ASTBURY, The Moral tale in France and Germany 1750-1789, Oxford, Voltaire

Foundation, 2002, pp. 223.

1 Il lavoro di Katherine Astbury si compone di otto capitoli racchiusi da un'introduzione e da una conclusione; in esso l'autrice intende offrire un excursus sullo sviluppo del «moral tale» in Francia e in Germania, a partire dal 1750, anno in cui sarebbe stato inventato da Jean-François Marmontel, fino al 1789.

2 Sebbene racconti a carattere edificante fossero in voga già dalla fine del XVII secolo, con Marmontel, scrittore dotato di straordinario talento per la «short fiction», si ha uno scavo in profondità nei difetti del mondo secondo il concreto punto di vista dei personaggi, coinvolgendo direttamente il lettore che, non più osservatore distaccato, è protagonista attivo delle vicende narrate. Genere di vasta eco, il «conte moral» rappresenta un affresco dei costumi, delle manie, delle eccentricità ed imperfezioni della società del tempo, con una messa a fuoco dei conflitti tra vizi e virtù, fungendo da correttivo sociale e plasmando una nuova identità per la nobiltà e la borghesia.

3 Sia in Francia che in Germania il genere prende le mosse dallo sviluppo dei periodici, sulla scia dei settimanali inglesi, per poi seguire un'evoluzione differente. Il «conte moral» conserva le caratteristiche della tradizione orale dei «salons», dov'è accordato molto più spazio alla «légèreté» e alla «finesse» che alla «moralité»; il «moralische Erzählung» trova il suo canale di diffusione privilegiato nei settimanali a scopo morale, rivolti in prevalenza alle famiglie. Se in un primo momento - 1750-1760 - il racconto tedesco attinge prepotentemente alle fonti francesi, in seguito gli autori cercano di conformarsi alla realtà locale e alle esigenze dei fruitori tedeschi; da ciò l'emergere di sostanziali differenze tematiche tra scrittori francesi e tedeschi: i primi si soffermano 
soprattutto sui costumi della società, i secondi esplorano la coscienza individuale. Tale distinzione è palese se si prendono in esame le opere di Bernardin de Saint-Pierre e Schiller.

4 Gli anni '60 segnano in Francia il risveglio della coscienza sociale, sotto l'effetto del pensiero rousseauiano e della «sensibilité». Esaltando la semplicità della vita bucolica e la superiorità dell'«uomo naturale», il racconto morale si converte in veicolo deputato alla promozione di un programma di riforme sociali e pedagogiche. L'attenzione crescente degli spiriti più sensibili alle incongruenze sociali conferisce al «conte moral» i tratti di un «conte social» secondo la più genuina tradizione illuministica; la critica investe un duplice piano: sociale - pregiudizi di classe, egoismi, ipocrisie - e politico tirannie, oppressioni, macchinazioni infernali del potere, trovando, rispettivamente, in Baculard e d'Ussieux le voci più infervorate.

Dal 1770 in poi si assiste, in Germania, al proliferare di una letteratura autoctona, non del tutto scevra di emulazioni del modello francese. Le idee di Rousseau sulla natura e sulla bontà innata dell'uomo, sottratto alla corruzione della società e calato nella dimensione incontaminata dell'ambiente rurale, costituiscono l'humus ideale per lo «Sturm und Drang», come attesta il Werther di Goethe. Nel panorama letterario del tempo, Sophie von La Roche è impareggiabile nel dipingere l'intreccio di valori, quali virtù, tolleranza, nobiltà di cuore e duro lavoro, valori di cui è depositaria in primis la classe media. Parallelamente alla situazione in Francia, anche gli scrittori tedeschi Möser, Schubart, Meißner, Wolf - riscoprono gradualmente il potenziale della «short fiction» come strumento di critica politica e sociale; dopo essersi preoccupati di sviluppare un senso di identità nazionale, si vanno via via concentrando su questioni legate al loro specifico contesto, denunciando gli abusi di chi detiene il potere e sposando la causa delle classi più indigenti.

6 È interessante rilevare che in entrambi i paesi gli autori non sono animati da uno spirito rivoluzionario o dal desiderio di sovvertire lo status quo, ma preferiscono la via dell'adattamento e della conciliazione, vagheggiando una forma di esistenza migliore per tutti - «le juste milieu» - che riflette l'ispirazione eudemonistica della filosofia dei Lumi.

7 A partire dal 1780 si registra uno sviluppo letterario del racconto morale sia in Francia che in Germania, sì da rendere la «short fiction» un genere a pieno diritto; a tal fine si propugna il superamento della struttura troppo semplicistica e della caratterizzazione eccessivamente rigida dei personaggi: come sostiene René Godenne, «l'opposition de caractères apparait trop artificielle - d'un côté les bons, de l'autre les mauvais - pour correspondre à une réalité effective». Innumerevoli scrittori si sforzano di superare i limiti angusti del «conte moral», sondando questioni morali più complesse e cimentandosi in un'indagine psicologica sempre più sottile e profonda, per quanto non sempre riuscita. La critica è unanime nel riconoscere in Diderot l'unico autore realmente capace di rompere gli schemi convenzionali, con un progressivo slittamento da trame stravaganti e specifici esempi di moralità ad una raffigurazione più attenta alla cura del dettaglio realistico e alla denuncia sociale. In uno stretto connubio tra realtà e finzione realizzato sul piano del dialogo che si snoda attorno al racconto, lo scrittore giudica le azioni umane oggettivamente, su una base individuale, senza doverle ricondurre ai sistemi artificiali e stereotipati imperanti nei "contes moraux» del tempo. 
8 Il testo si chiude con una ricca bibliografia, seguita dall'indice dei racconti presi in esame ed un indice degli autori citati. 